\title{
Differential binding of $(+)$ and $(-)$ gossypol to plasma protein and their entry into rat testis
}

\author{
J. M. Wang, L. Tao, X. L. Wu, L. X. Lin, J. Wu, M. Wang and G. Y. Zhang \\ Department of Pharmacology, Nanjing Institute of Materia Medica, 26 Ma Jia Jie, Nanjing \\ 210009, People's Republic of China
}

\begin{abstract}
Summary. Concentrations of $(+)$ and $(-)$ gossypol were measured by high performance liquid chromatography after they were incubated with plasma proteins in vitro. The concentration of $(-)$ gossypol decreased more than the concentration of $(+)$ gossypol. A similar decrease in free gossypol concentrations in the blood plasma of rats was observed after intravenous infusion of gossypol enantiomers. The concentration of $(-)$ gossypol was also found to be lower than the concentration of $(+)$ gossypol at the blood-testis barrier. The biological effect of $(-)$ gossypol probably results from its stereospecific binding to extra- and intracellular proteins in vivo and inhibition of the biological activity of some proteins.
\end{abstract}

Keywords: gossypol enantiomers; HPLC; protein binding; blood-testis barrier; rat

\section{Introduction}

The reason for the differences between the in vitro and in vivo activities of gossypol enantiomers is still unknown. Although both enantiomers show similar spermicidal potency in vitro (Kim et al., 1984), only (-) gossypol is active as an antifertility agent in male hamsters and rats (Wang et al., 1984; Matlin et al., 1985; Lindberg et al., 1987). It has been proposed (Tanphaichtr et al., 1988) on the basis of in vitro studies, that the $(+)$ gossypol is more readily bound to serum proteins, so that, at a given concentration, $(-)$ gossypol would remain mainly in the free form in contrast to $(+)$ gossypol. The present investigation was undertaken to clarify whether gossypol enantiomers bind in different ways to plasma proteins and whether they differ in their ability to cross the blood-testis barrier.

\section{Materials and Methods}

\section{Materials}

Gossypol enantiomers were provided by the Special Programme in Human Reproduction, World Health Organization, Geneva, and by S. A. Matlin (Department of Chemistry, The City University, London, UK). The optic purities for both enantiomers as checked by polarimeter (Perkin Elmer, Model 24l, USA) were 99.5-99.9\%. The racemic gossypol acetic acid $(99.9 \%$ pure) was also provided by WHO.

\section{Gossypol assay}

Gossypol concentrations in all the samples were determined by means of high performance liquid chromatography (High Performance Liquid Chromatograph, LC-4A, Shimadzu, Japan) with an additional electrochemical detector (LKB, 2143, Sweden), as described previously (Wang et al., 1988, 1989). Briefly, plasma or rete testis fluid was treated with acetonitrile to precipitate the protein fraction. The supernatant fluid was added to EDTA and buffer solution ( $\mathrm{pH} 4.8)$ which was extracted with chloroform and dried by nitrogen flow for determination of gossypol content. The dried sample was redissolved in the mobile phase (methanol and buffer) before injecting it into the HPLC apparatus, column $\mathrm{C}_{18}(5 \mu \mathrm{m}), 250 \mathrm{~mm} \times 4.6 \mathrm{~mm}$ i.d. (Du-Pont, USA) was selected for analysis. The flow rate was 
$1.0 \mathrm{ml} \mathrm{min}{ }^{-1}$. The minimal detectable amount was $0.1 \mathrm{ng}$ by electrochemical detector. The recovery rate of gossypol standard ( $1 \mathrm{ng}$ ) after extraction was $92.3 \%$. Both gossypol enantiomers and the racemic gossypol showed the same retention time in the chromatogram.

\section{In vitro study}

Gossypol stock solution was prepared by dissolving $2 \mu \mathrm{moll}^{-1}$ gossypol enantiomer in $60 \mu$ lof ethanol which was then diluted to $12 \mathrm{ml}$ with deoxygenated distilled water. The maximal final concentration of ethanol in the solution was $0.5 \%$. The equivalent of both enantiomers was verified by ultraviolet spectrophotometry. This solution was allocated into $0.5 \mathrm{ml}$ aliquots in which plasma freshly collected from rats was added in a proportion of $1: 4(\mathrm{w} / \mathrm{v})$, i.e. gossypol content in weight $(\mu \mathrm{g})$ to volume of plasma $(\mu \mathrm{l})$ added. The gossypol concentrations of such samples were measured in duplicate by means of HPLC before incubation and at I, 2 and $4 \mathrm{~h}$ after incubation at $37^{\circ} \mathrm{C}$. Control samples in which no plasma was added were incubated similarly for determination of gossypol concentrations.

\section{In vivo study}

Thirty Wistar rats weighing $382 \pm 11 \mathrm{~g}$ (SEM) were used in this study. Gossypol enantiomers were prepared in aqueous solution and packed in ampoules filled with nitrogen gas for intravenous infusion as previously described (Wang et al., 1989).

The rats were anaesthetized with sodium pentobarbital (Nembutal: Abbott Laboratories, Switzerland, $50 \mathrm{mg} \mathrm{kg}^{-1}$, i.p.) and the gossypol preparations were infused through the jugular vein by means of an infusion pump (Harvard Apparatus, Model 975A, USA) at a speed of $0.026-0.1 \mathrm{ml} \mathrm{min}-1$ depending on the physical status of the animal; this took $\left[\cdot 5 \mathrm{~h}\right.$ for a dose of $30 \mathrm{mg} \mathrm{kg}^{-1}$. Blood samples were collected from an indwelling catheter in the carotid artery filled with heparin $\left(500 \mathrm{i} . \mathrm{u} . \mathrm{ml}^{-1}\right)$ as soon as the infusion of gossypol had finished and at 1,2 and $4 \mathrm{~h}$ after infusion. The samples were then centrifuged immediately for separation of the plasma fraction before extraction and HPLC analysis.

The animals were anaesthetized with sodium pentobarbital, and the bilateral efferent ducts of testes were ligated through an abdomina! incision. Twenty hours later, the animals were anaesthetized again and the distended efferent duct was cannulated under a dissecting microscope by inserting a polyethylene tube pulled to a fine tip, through which the rete testis fluid was collected continuously for $4 \mathrm{~h}$ after intravenous administration of gossypol preparation. A blood sample was collected at the end of this period. The plasma concentration was expressed in $\mu \mathrm{g} \mathrm{ml}^{-1}$, but the concentration of gossypol in rete testis fluid was expressed in terms of ng per $4 \mathrm{~h}$ of collection, since the initial portion of the sample was the accumulated fluid before gossypol administration.

\section{Results}

\section{In vitro study}

In the presence of plasma protein the concentration of $(-)$ gossypol decreases more than does the concentration of $(+)$ gossypol, which is maintained at a higher level (Fig. 1). Since both enantiomers decrease in a similar way with time of incubation, there is no significant difference between the slopes calculated by linear regression in both cases $(P>0.05)$. However, in the absence of plasma protein, the concentration of both isomers remained constant without being degraded during the $4 \mathrm{~h}$ incubation. Although equivalent concentrations of both enantiomers were applied, there was a marked difference in their initial concentrations before incubation in the presence of plasma protein. The differential binding of free gossypol to plasma protein occurs as soon as gossypol and plasma are mixed together.

\section{In vivo study}

The concentration-time curve for $(-)$ gossypol is at the lowest level in sharp contrast to $(+)$ gossypol which is maintained at a much higher level, as in the in vitro study. The racemic curve lies between the curves for $(+)$ and $(-)$ gossypol. The measurements of free gossypol concentrations start as soon as the infusion of this compound is finished which takes $1.5 \mathrm{~h}$. The marked difference in the initial points observed in this case signifies the differential binding of free gossypol to plasma protein that has occurred during the infusion period. 


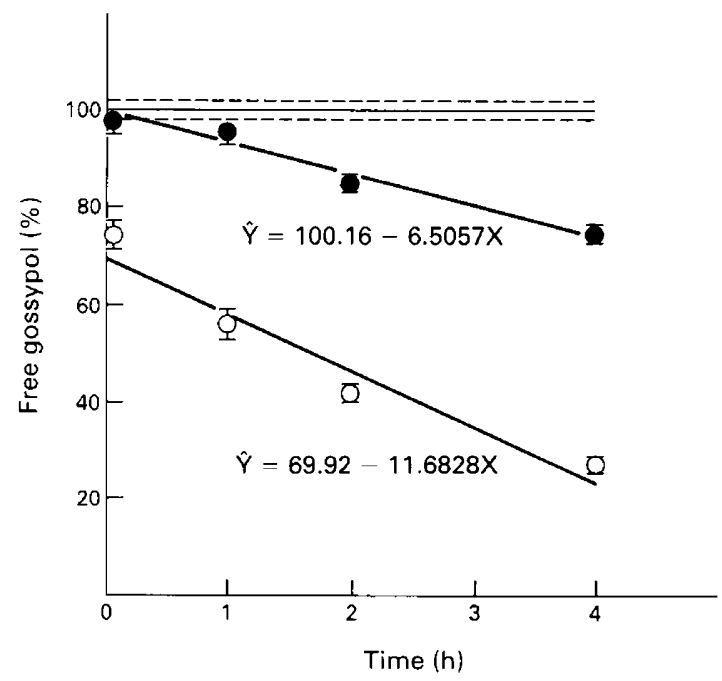

Fig. 1. Variation of free gossypol concentrations with time when $(+)$ and $(-)$ gossypol were incubated in vitro in presence of plasma protein. ( - $-(+)$ gossypol; $(\mathrm{O}-\mathrm{O}):(-)$ gossypol. The line within the dotted lines denotes the control level $(100 \%)$ when both enantiomers were incubated in the absence of plasma protein. Values are mean \pm SD for four samples.

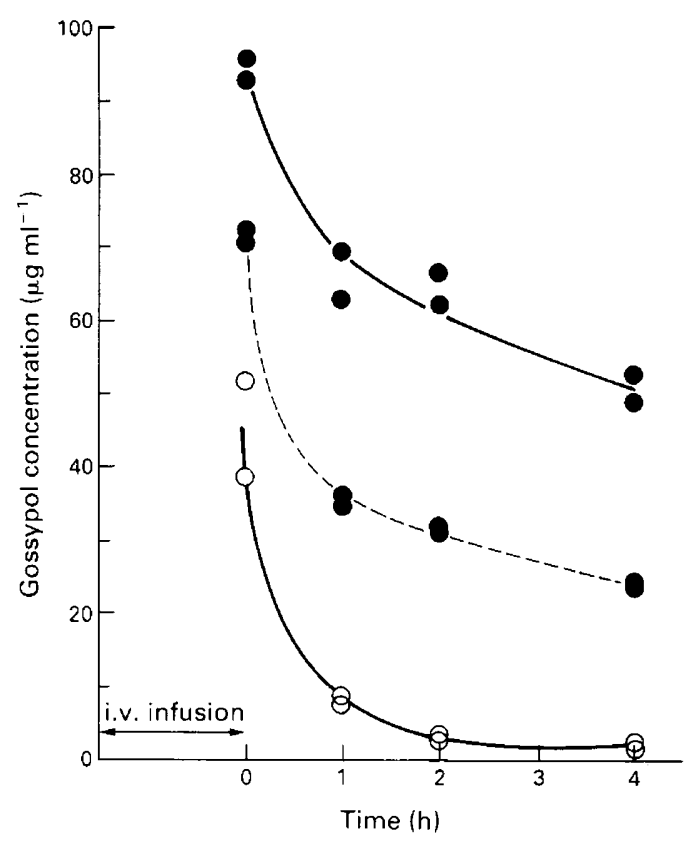

Fig. 2. Variation in plasma gossypol concentrations with time after a single intravenous dose $\left(30 \mathrm{~m} \mathrm{~kg}^{-1}\right)$ of gossypol enantiomers. ( — $)$ : (+) gossypol; $(\mathrm{O} \bigcirc)$ : $(-)$ gossypol; (-- - ) : $( \pm)$ gossypol acetate. 
The difference in the fate of the two gossypol enantiomers in vivo after intravenous administration can also be expressed quantitatively in terms of various pharmacokinetic parameters calculated from the concentration-time data (Fig. 1) which fit the two-compartment model by computer processing. The most striking difference between $(+)$ and $(-)$ gossypol is manifested in elimination capacity $(\beta), t_{\frac{1}{2}} \beta$, elimination rate constant $\left(K_{10}\right)$, clearance $(C L)$, and area under curve (AUC) which are parameters (Table 1), indicating the behaviour of this compound in the elimination phase, including $V_{\text {area }}$ which is five times higher in the case of $(-)$ gossypol. The other parameters reflecting the pharmacokinetics in the distribution phase do not differ between the $(+)$ and $(-)$ isomers, as shown in the values of $\alpha, t_{1} \alpha, K_{12}, K_{21}$ and volume of central compartment $\left(V_{\mathrm{c}}\right)$. The higher values $\beta, K_{10} \mathrm{CL}$ with a corresponding shorter elimination $t_{\frac{1}{2}}\left(t_{\frac{1}{2}} \beta\right)$ and smaller AUC in the case of $(-)$ gossypol suggest that the more rapid disappearance of $(-)$ gossypol in the blood plasma after intravenous administration is due mainly to its greater extent of elimination from the central compartment under such circumstances.

Table 1. Pharmacokinetic parameters for $(+),(-)$, and $( \pm)$ gossypol in rats after a single intravenous dose $\left(30 \mathrm{mg} \mathrm{kg}^{-1}\right)$

\begin{tabular}{lccc}
\hline Parameter & (+) Gossypol & $(-)$ Gossypol & $( \pm)$ Gossypol \\
\hline$\alpha\left(\mathrm{h}^{-1}\right)$ & 2.082 & 2.337 & 1.844 \\
$\beta\left(\mathrm{h}^{-1}\right)$ & 0.096 & 0.491 & 0.130 \\
$t_{i} \alpha(\mathrm{h})$ & 0.346 & 0.297 & 0.375 \\
$t_{1} \beta(\mathrm{h})$ & 7.373 & 1.424 & 5.308 \\
$K_{12}\left(\mathrm{~h}^{-1}\right)$ & 0.369 & 0.533 & 0.654 \\
$K_{21}\left(\mathrm{~h}^{-1}\right)$ & 1.691 & 0.764 & 1.102 \\
$K_{10}\left(\mathrm{~h}^{-1}\right)$ & 0.118 & 1.529 & 0.218 \\
$V_{\text {area }}\left(1 \mathrm{~kg}^{-1}\right)$ & 0.389 & 2.026 & 0.700 \\
$V_{\mathrm{c}}\left(1 \mathrm{~kg}^{-1}\right)$ & 0.317 & 0.659 & 0.418 \\
$C^{-1}\left(1 \mathrm{~h}^{-1} \mathrm{~kg}^{-1}\right)$ & 0.037 & 0.987 & 0.092 \\
AUC $\left(\mathrm{mg} \mathrm{h}^{-1} \mathrm{l}^{-1}\right)$ & 810.5 & 32.20 & 324.8 \\
\hline
\end{tabular}

Values are the mean of two animals indicated in Fig. 1.

$\alpha$ : distribution capacity; $\beta$ : elimination capacity; $k_{12}$ : central to peripheral compartment rate constant; $k_{21}$ : peripheral to central compartment rate constant; $k_{10}$ : elimination rate constant; $V_{\text {area }}$ : volume of distribution; $V_{c}$ : volume of central compartment; $\mathrm{CL}$ : clearance; AUC: area under curve.

The concentration patterns of free gossypol for different enantiomers are virtually identical for the plasma and rete testis fluid $4 \mathrm{~h}$ after intravenous administration (Fig. 3). The sharp concentration gradient of gossypol between the blood plasma and rete testis fluid is reflected in the difference of the scales. In accordance with the gossypol concentration in blood plasma, the amount of $(+)$ gossypol present in rete testis fluid collected for $4 \mathrm{~h}$ after infusion is remarkably higher than that of the (-) gossypol; the racemic gossypol is intermediate between the other two isomers. The $(+)$ gossypol may therefore cross the blood-testis barrier much more readily because of its much higher plasma concentration and much greater concentration gradient. Much less $(-)$ gossypol crosses the blood-testis barrier because of its far lower plasma level and concentration gradient. In some cases, gossypol could barely be detected in rete testis fluid after a single intravenous dose of $(-)$ gossypol.

\section{Discussion}

The aldehyde groups present in the gossypol molecule may be readily bound to the free amino groups of the protein molecules to form a Schiff's base. This has been confirmed by the report that pretreatment of plasma with 2,4-dinitrofluorobenzene or aspirin which acrylates or acetylates the 

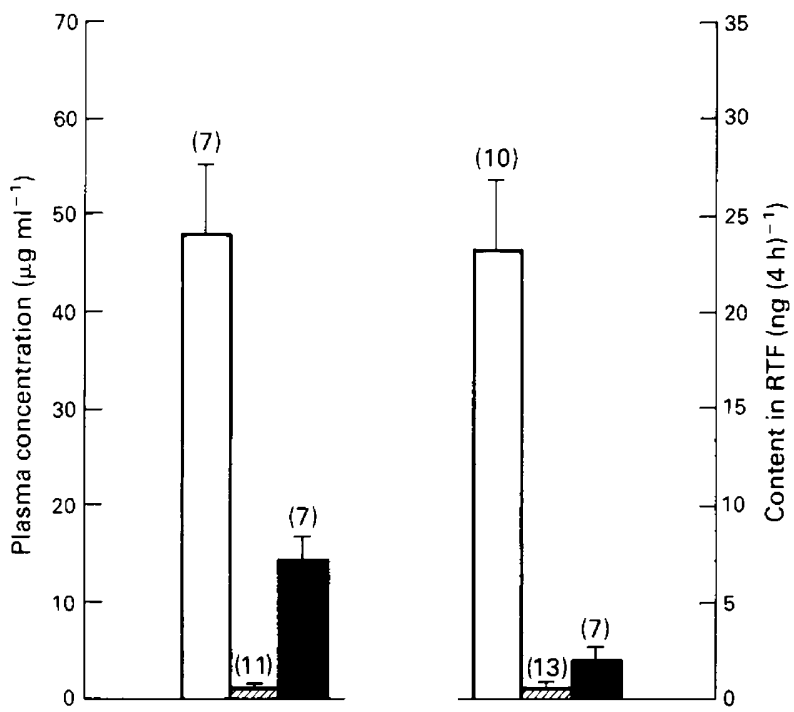

Fig. 3. The gossypol concentration of plasma and amount present in rete testis fluid (RTF) $4 \mathrm{~h}$ after a single intravenous dose $\left(30 \mathrm{mg} \mathrm{kg}^{-1}\right)$ of different gossypol enantiomers. Values are mean \pm SD for the numbers of samples indicated in parentheses. $(\square):(+)$ gossypol; $(\square):(-)$ gossypol; $(\boldsymbol{\square}):( \pm)$ gossypol acetic acid.

amino groups of protein can slow down the rate of disappearance of the free $(-)$ gossypol in plasma (Wu \& Reidenberg, 1990). The covalent linkage formed in the Schiff's base could not be separated unless the protein molecule is hydrolysed. During the process of HPLC, the protein fraction in the biological samples has to be precipitated and discarded, together with the proteinbound gossypol; thus only the free gossypol is measured.

Because of the protein-binding property of this compound, the cytotoxicity of gossypol can be protected by serum protein, as reflected in the proportionate increase of $\mathrm{EC}_{50}$ (concentration causing $50 \%$ inhibition of growth) with the increase of serum concentration in different cell cultures (Haspel et al., 1984; Joseph et al., 1986; Tanphaichtr et al., 1988). The $\mathrm{EC}_{50}$ for (-) gossypol was much lower than that of $(+)$ gossypol in the presence of serum protein. It is possible that, under such circumstances, the (-) gossypol would remain mainly in a free form because of the relatively weaker binding of this enantiomer to serum albumin. This is completely contradictory to our findings and the data of Wu \& Reidenberg (1990) that $(-)$ gossypol rather than the $(+)$ gossypol was bound much more readily to plasma protein.

The marked difference in the pharmacokinetics of gossypol enantiomers in vivo mentioned above reveals that (-) gossypol is eliminated from the circulating blood much more readily than the $(+)$ isomer. This is in agreement with the pharmacokinetic study of Wu et al. (1986). Elimination of free gossypol from the blood plasma involves intercompartmental transfer, metabolism and excretion through the hepatic or renal routes as well as protein-binding mechanism. Since the $K_{12}$ values of $(+)$ and $(-)$ gossypol are the same, it seems unlikely that $(-)$ gossypol is transferred from the central to peripheral compartment more readily which may partially account for its rapid disappearance from the plasma. As far as the blood-testis barrier is concerned, the concentration of $(-)$ gossypol within the barrier is much lower than the concentration of $(+)$ gossypol in accordance with their plasma concentrations after a single intravenous dose. Owing to the fact that a time-dependent decline of free gossypol concentration in the presence of plasma protein is also observed in vitro, it is assumed, therefore, that the differential bindings of gossypol enantiomers to plasma protein may play an important role in the different behaviour of these two isomers in the blood plasma after intravenous administration. 
Thus it is surprising that only (-) gossypol, which is present in the free state at very low concentration within the male genital tract, is biologically active. However, the in vitro studies showed that the $\mathrm{EC}_{50}$ of the (-) gossypol is always much lower than that of (+) gossypol, especially in the presence of serum.

Den Boer \& Grootegoed (1988a, b) reported that the stereospecific protein-binding mechanism of gossypol is not confined to plasma protein; it may also be readily bound to other extra- and intracellular proteins with a high affinity for gossypol at the adluminal side of the blood-testis barrier, possibly some proteins therein bind gossypol more strongly than plasma albumin. The interaction of $(-)$ gossypol with the cellular proteins must also be stereospecific and results in inhibition of the biological activity of the proteins even at very low concentration and there is apparently no such specific interaction of $(+)$ gossypol with cellular components concerned. This may account for the unique biological action of $(-)$ gossypol in vivo.

Financial support was received from the Special Programme of Research, Development and Research Training in Human Reproduction, World Health Organization, Geneva, Project 88033. We thank G. Y. Wen and L. L. Xu for their help in the preparation of the gossypol formulations.

\section{References}

Den Boer, P.J. \& Grootegoed, J.A. (1988a) Mechanism of action of $(-)$ gossypol on ATP production in isolated hamster spermatids. Journal of Reproduction and Fertility 83, 693 700.

Den Boer, P.J. \& Grootegoed, J.A. (1988b) Differential effects of $(+)$ and $(-)$ gossypol enantiomers on LDH-C 4 activity of hamster spermatogenic epithelium in vitro. Journal of Reproduction and Fertility 83, 701-709.

Haspel, H.C., Ren, Y.F., Watanabe, K.A., Sonnenberg, M. \& Corin, R.E. (1984) Cytocidal effect of gossypol on cultured murine erythroleukemia cells is prevented by serum protein. Journal of Pharmacology and Experimental Therapeutics 229, 218-225.

Joseph, A.E.A., Matlin, S.A. \& Knox, P. (1986) Cytotoxicity of enantiomers of gossypol. British Journal of Cancer 54, 511-513.

Kim, I.C., Waller, D.P., Marcelle, G.B., Cordell, G.A. \& Fong, H.H.S. (1984) Comparative in-vitro spermicidal effects of (+)-gossypol, ( \pm )-gossypol, (-)gossypol and gossypolone. Contraception 30, 253259.

Lindberg, M.C., Naqvi, R.H., Zhou, R.H., Bialey, G. \& Blye, R.P. (1987) Comparative antifertility effects of gossypol enantiomers in male hamsters. International Journal of Andrology 10, 619-623.

Matlin, S.A., Zhou, R.H., Bialey, G., Blye, R.P., Naqvi, R.H. \& Lindberg, M.C. (1985) (-)-gossypol: an active male anti-fertility agent. Contraception 31, 141-149.

Tanphaichtr, N., Fitzgerald, L.M. \& Matlin, S.A. (1988) Differential effects of $(+)$ and $(-)$ gossypol enantiomers on mitochondrial function and proliferation of cultured $\mathrm{TM}_{4}$ cells. Journal of Andrology 9, 270-277.

Wang, J.M., Qiu, J.P., Wu, X.L., Zhang, Z.R., Shao, Y. \& Cao, R.Q. (1988) The correlation between the gossypol contents in blood plasma, rete testis fluid, and cauda epididymal fluid following chronic treatment with gossypol in rats. Journal of Andrology 9 , $397-402$.

Wang, J.M., Wen, G.Y., Zhang, Z.R., Wu, X.L., Jiang, D.H., Tao, L., Cao, R.Q. \& Zhou, Q. (1989) The entry of gossypol across the blood-testis barrier in rats. Contraception 39, 569-575.

Wang, N.G., Guan, M.Z. \& Lei, H.P. (1984) Effects of $(-)$ and $(+)$ gossypol on fertility of male rats. Acta Pharmaceutica Sinica 19, 932-934.

Wu, D.F. \& Reidenberg, M.M. (1990) Stereoselective interaction between gossypol and rat plasma. Contraception 41, 377-388.

Wu, D.F., Yu, Y.W., Tang, Z.M. \& Wang, M.Z. (1986) Pharmacokinetics of ( \pm )-, (+)-, and (-)-gossypol in humans and dogs. Clinical Pharmacology and Therapeutics 39, 613-617.

Received 8 April 1991 